Article

\title{
Development of Vacuum Insulation Panels with Utilization of Organic By-Products ${ }^{+}$
}

\author{
Jiří Zach *, Vítězslav Novák, Jitka Peterková \\ Faculty of Civil Engineering, Brno University of Technology, Veveři 331/95, 60200 Brno, Czech Republic; \\ novak.v@fce.vutbr.cz (V.N.); peterkova.j@fce.vutbr.cz (J.P.); bubenik.j@fce.vutbr.cz (J.B.) \\ * Correspondence: zach.j@fce.vutbr.cz; Tel.: +420-541-147-516 \\ † This is an extended version of our paper published in the Central European Symposium on Building Physics \\ 2019, Prague, Czech Republic, 2-5 September 2019.
}

Received: 19 December 2019; Accepted: 26 February 2020; Published: 4 March 2020

check for updates

\begin{abstract}
The need for the development of new, advanced building materials increases every year, especially due to the necessary diminution of energy performance for building structures and for building production itself (including the production of building materials). Along with the energy performance problems in construction, the issue of $\mathrm{CO}_{2}$ emission associated with building and the production of building materials is also important. In the field of advanced thermal insulation materials, vacuum insulation panels (VIPs) give the best results. However, their high-energy performance and material consumption present a problem. This work represents an initial part of the development of alternative insulators, based on agricultural and textile industry waste usable in the production of VIP. This article recapitulates basic knowledge regarding key thermal insulation properties of developed insulators and their fire reactions, which impact possible usage in building structures.
\end{abstract}

Keywords: vacuum insulation panel; thermal insulation material; alternative insulator

\section{Introduction}

Vacuum insulation panels (VIPs) — which are made of core materials (thermal insulation materials with a very fine porous structure and high total open porosity $[1,2])$ and a glass-barrier envelope (multi-laminated foils or foils with aluminum film [1,2]) - represent the thermal insulation of the future and could contribute greatly to the improvement of energy efficiency in buildings. The thermal insulation features are significantly better than in commonly used materials, and VIPs show up to ten times higher thermal resistance. Although the origin of VIPs was recorded in the first half of the 20th century, their first use in construction in the USA dates back to 1999 [1]. Currently, VIPs are mostly used in the freezing and refrigeration industry, representing approximately $60 \%$ of production. Another major use of VIPs is in packaging and shipping boxes. In the construction industry, approximately $10 \%$ of VIP production uses thermal insulating material [2]. Service life and demanding work requirements during installation are some of the reasons that account for the lower use of VIPs in the construction industry. Many research teams throughout the world are working on the development of VIPs and studying their behavior with respect to pressure. The selection of core materials plays a key role in producing the high-quality thermo-insulating features of VIPs. Today, inorganic materials based on aerogel or microsilica, powdered perlite, and various glass-fibered materials are commonly used as core insulation materials. For the increased durability of VIPs and the elimination of the outgassing effects of some types of core insulators, getters and dryers are used and embedded inside VIPs [2]. However, many studies have shown that alternative thermal insulation materials can be used as core insulators for VIPs [1-6]. 
This article focuses on the results of the study examining the behavior of alternative fibrous insulators when used for VIPs under reduced pressure. In this case, these are insulators made of very fine and short fibers that were obtained from filters of the tear line and cannot be used for the production of classic insulators produced by air-lay technology (unlike other and previously published works) [7].

\section{Methodology}

The total effective thermal conductivity $\lambda_{\text {eff }}$ of VIPs is given by the sum of the solid conduction $\lambda_{s}$, the gaseous conduction $\lambda_{g}$, and the thermal radiation $\lambda_{\mathrm{r}}$. The solid conduction $\lambda_{\mathrm{s}}$ depends on the structure and material properties of the core. The gaseous conduction $\lambda_{\mathrm{g}}$ by residual gases depends on the gas pressure that increases with time through the infusion of atmospheric gases and outgassing of the inner material. Thermal radiation $\lambda_{\mathrm{r}}$ depends on the structure and optical properties of the core.

$$
\lambda_{\text {eff }}=\lambda_{\mathrm{s}}+\lambda_{\mathrm{g}}+\lambda_{\mathrm{r}}+\lambda_{\mathrm{tb}}[\mathrm{mW} /(\mathrm{m} . \mathrm{K})]
$$

Therefore, $\lambda_{\mathrm{s}}$ and $\lambda_{\mathrm{r}}$ are not dependent on gas pressure, and they have the lowest thermal conductivity of core insulation $\lambda_{0}$ :

$$
\lambda_{0}=\lambda_{\mathrm{s}}+\lambda_{\mathrm{r}}[\mathrm{mW} /(\mathrm{m} \cdot \mathrm{K})]
$$

The gaseous conduction $\lambda_{\mathrm{g}}$ by residual gases depends on the gas pressure, which increases over time by the infusion of atmospheric gases and outgassing of the inner material [8].

Typical for each type of insulation material is the dependence of thermal conductivity on pressure. Depending on the pore size, the insulator's sensitivity to the change in pressure also varies. This characteristic is described by the parameter $p_{1 / 2}$ pressure at which the gas's thermal conductivity reaches the value of one half of $\lambda_{\mathrm{g}}=25.5 \mathrm{~mW} /(\mathrm{m} \cdot \mathrm{K})$ in the case of air. The parameter $p_{1 / 2}$ depends on the mean pore size of the material $\delta$, the diameter of the gas molecules $d_{g}$, the temperature $\mathrm{T}$, the gas type constant $\beta$ (depending on the gas type), and the Boltzmann constant $k_{B}$ [8] (see Equation (3) below).

$$
p_{1 / 2 \cdot g}=\frac{T}{\delta} \cdot \frac{2 \cdot \beta \cdot k_{B}}{\sqrt{2} \cdot \pi \cdot d_{g}^{2}}
$$

It is generally known that a core material must be porous in order to ensure an easy evacuation. Ideally, it should have open porosity, long-term structural stability, and minimal impact on thermal conduction. It is a proven fact that the smaller the pores (with a very high total open porosity), the better the thermal insulation features of the final VIP [5]. The reduction of inner pressure on most of the thermal insulation leads to an improvement in performance. This improvement is caused by a gradual reduction of heat transfer under the influence of a flux in the porous structure of an insulator, and the reduction of thermal conduction via a gaseous phase contained in the insulator's pores. The dependence of the thermal conductivity coefficient on pressure is individual for every insulator type with open-porosity structure. It is generally known that a material with a finer porous structure is less sensitive to pressure changes in a low pressure/vacuum area. Conversely, materials with a higher share of larger pores are more sensitive to pressure changes. In addition, within the whole pressure range, from atmospheric pressure to a vacuum, the changes can alter the materials' thermal conduction [6].

\section{Results}

During the experimental works at Brno University of Technology's Faculty of Civil Engineering, the development of core insulators for VIPs took place with the use of secondary materials. New fiber types based on flax and cotton were selected as suitable raw materials, along with lint from the filters of textile tearing machines (see Figure 1). 


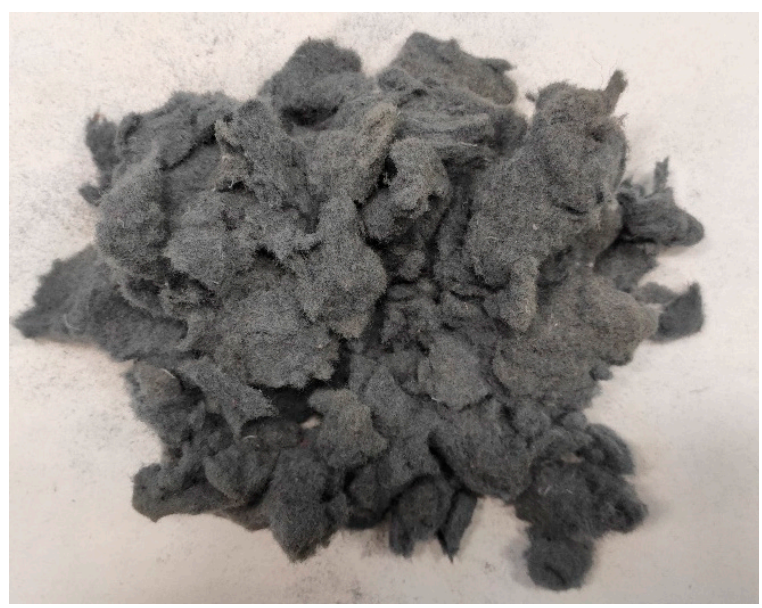

(a)

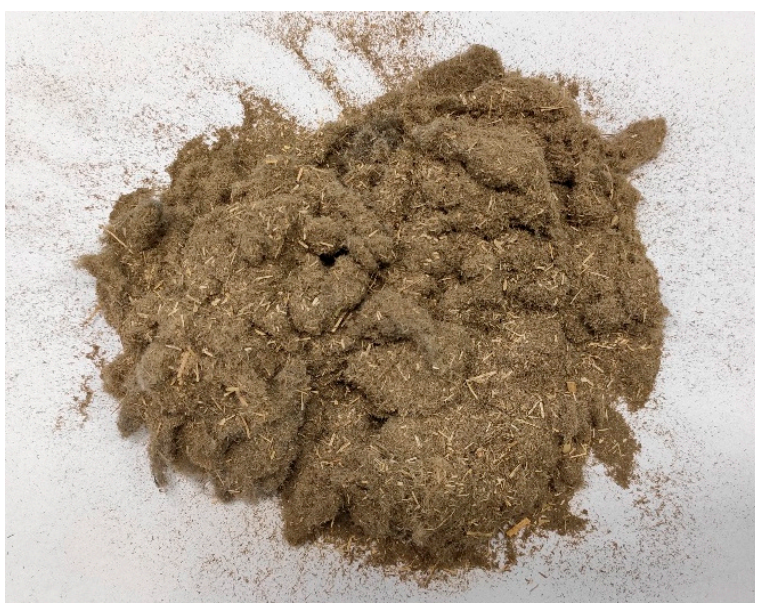

(b)

Figure 1. Photography of cotton (a) and flax (b) fibers.

Macroscopic and microscopic analyses (including optical (see Figure 2) and reflection electron microscopy-REM (see Figures 3 and 4)) were performed on fibers, and the following was observed:

- Both fiber types contain a large proportion of significantly fine fibers;

- The cotton sample is homogeneous; coarse samples of hemp shives are also included in the flax sample (this can be seen in the larger standard deviation in the case of flax-fiber thickness (see Table 1);

- The length of the fibers is lower in both cases, but the predominant proportion of fibers in the samples has a length of 10-20 $\mathrm{mm}$.

Table 1. Properties of core insulators (in accordance with EN 823, EN 12085, EN 1602, EN 826, EN 12431).

\begin{tabular}{|c|c|c|c|c|c|}
\hline Sample & $\begin{array}{l}\text { Thickness } \\
(\mathrm{mm})\end{array}$ & $\begin{array}{l}\text { Density } \\
\left(\mathrm{kg} / \mathrm{m}^{3}\right)\end{array}$ & $\begin{array}{l}\text { Square Weight } \\
\left(\mathrm{kg} / \mathrm{m}^{2}\right)\end{array}$ & $\begin{array}{c}\text { Compressive Stress at } \\
10 \% \text { Strain }(\mathrm{kPa})\end{array}$ & $\begin{array}{c}\text { Compressibility } \\
(\%)\end{array}$ \\
\hline Cotton & 15.60 & 119 & 1.86 & 0.26 & 34.7 \\
\hline Flax & 10.46 & 178 & 1.85 & 0.57 & 23.3 \\
\hline
\end{tabular}

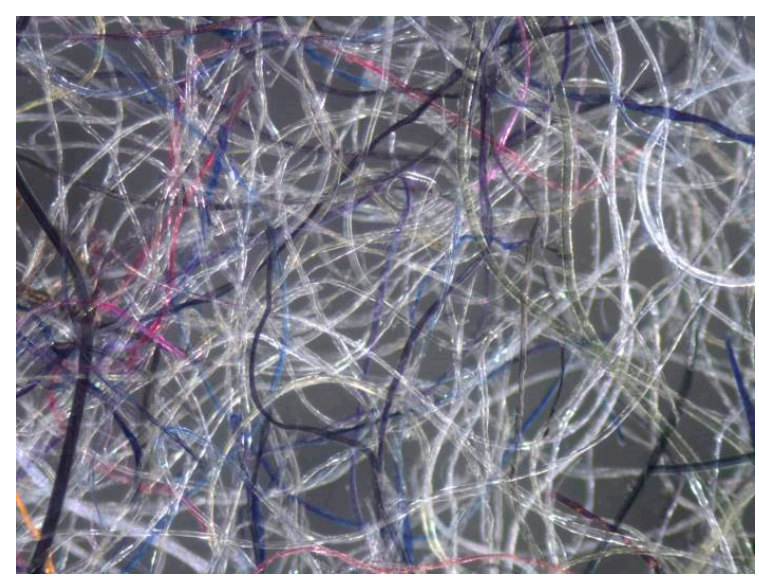

(a)

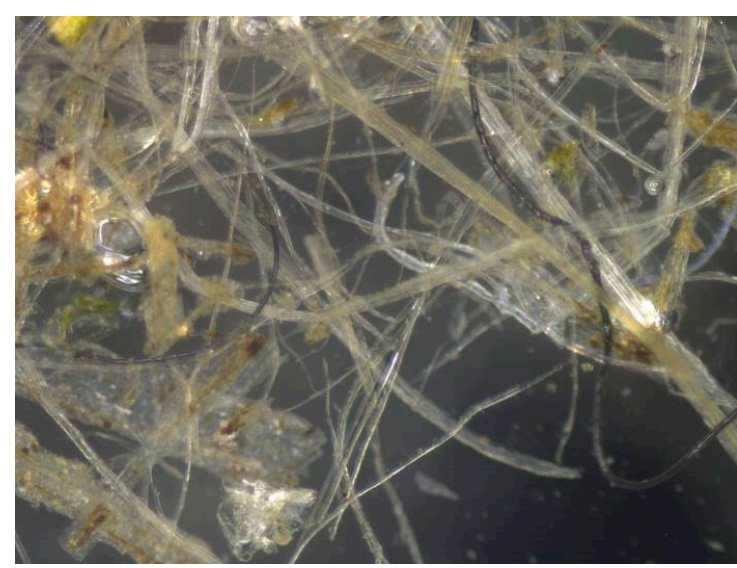

(b)

Figure 2. Photographs of cotton (a) and flax (b) fibers under optical microscope (magnification $5 \times$ ). 


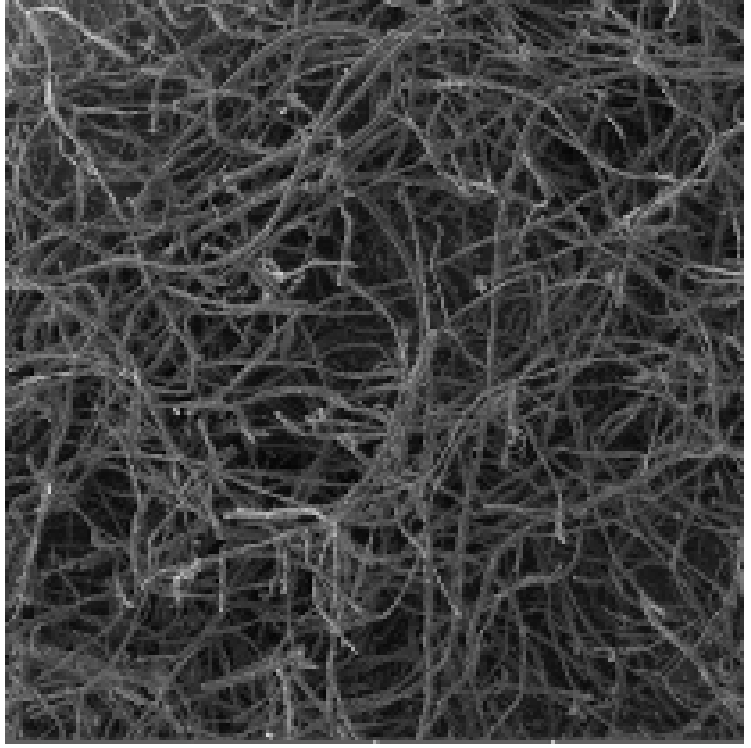

(a)

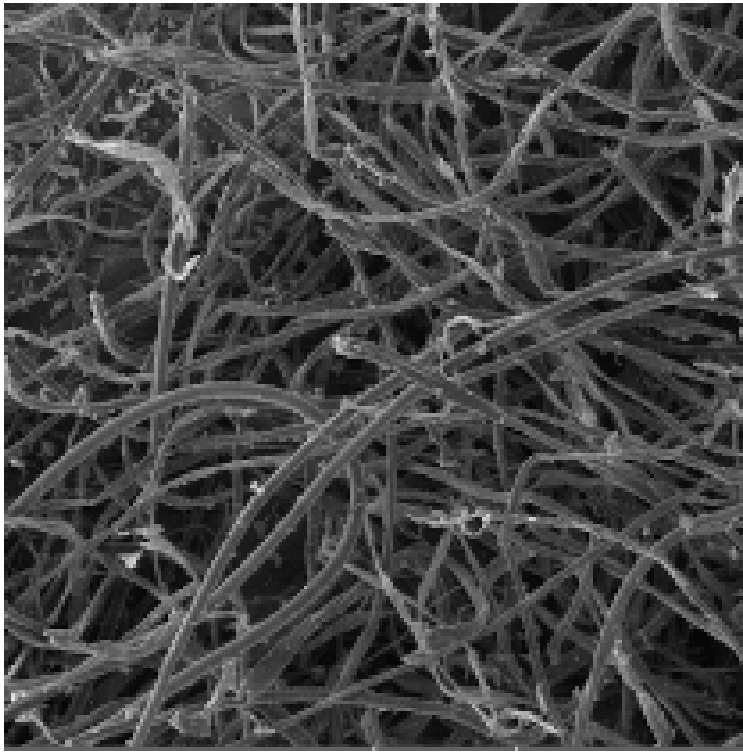

(b)

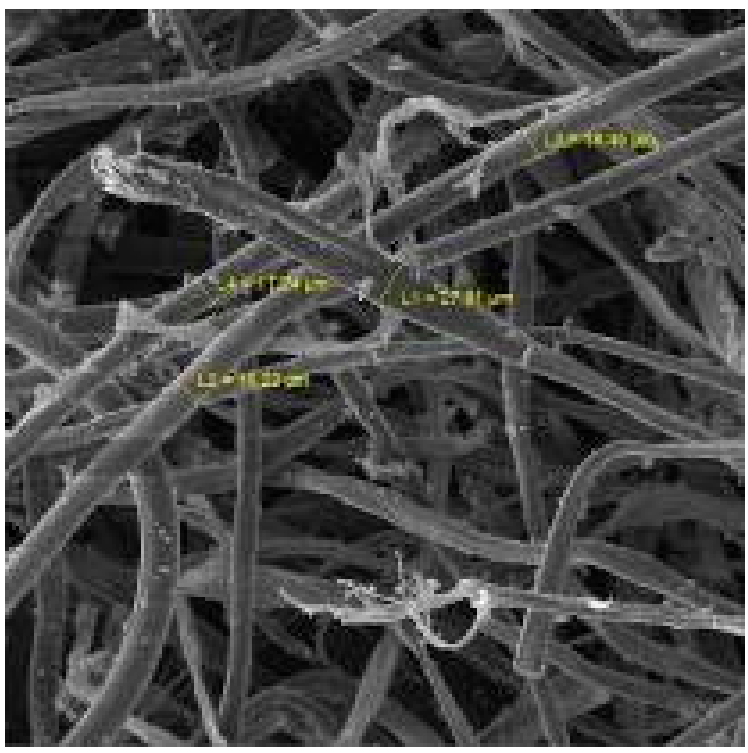

(c)

Figure 3. Photographs of cotton under REM microscope (magnification $100 \times($ a), $200 \times(\mathbf{b})$, and $500 \times(\mathbf{c})$ ).

The microscopic analysis confirmed the assumptions of the macroscopic analysis, and the length and thickness of both types of fibers were determined. The results are shown below:

- Cotton:

- Average fiber thickness, $12.49 \times 10^{-3} \mathrm{~mm}$ (standard deviation of $3.45 \times 10^{-3} \mathrm{~mm}$ );

- Average fiber length, $16 \mathrm{~mm}$ (standard deviation of $1 \mathrm{~mm}$ );

- Flax:

Average fiber thickness, $19.49 \times 10^{-3} \mathrm{~mm}$ (standard deviation of $11.66 \times 10^{-3} \mathrm{~mm}$ );

$\bigcirc \quad$ Average fiber length, $12 \mathrm{~mm}$ (standard deviation of $0.5 \mathrm{~mm}$ ). 


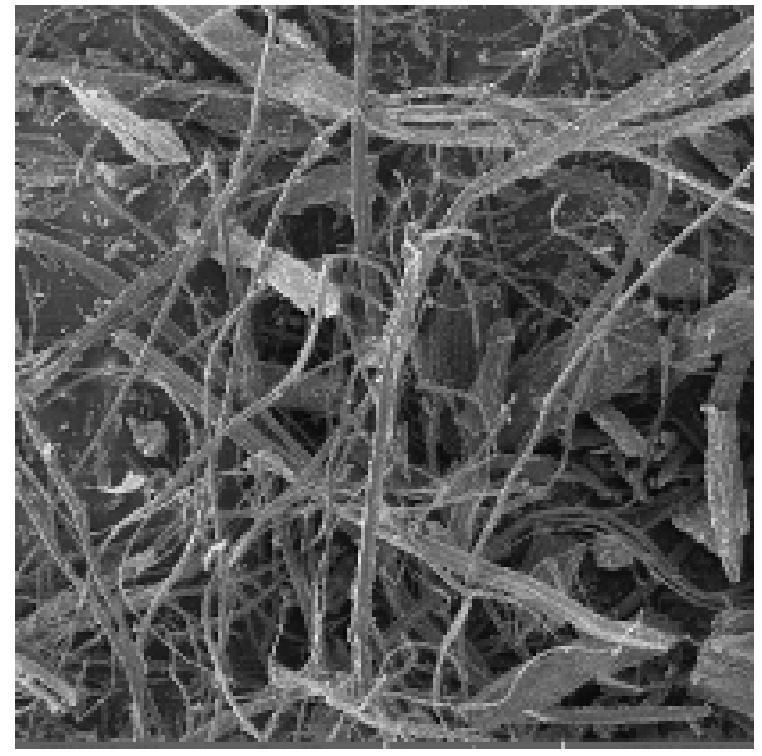

(a)

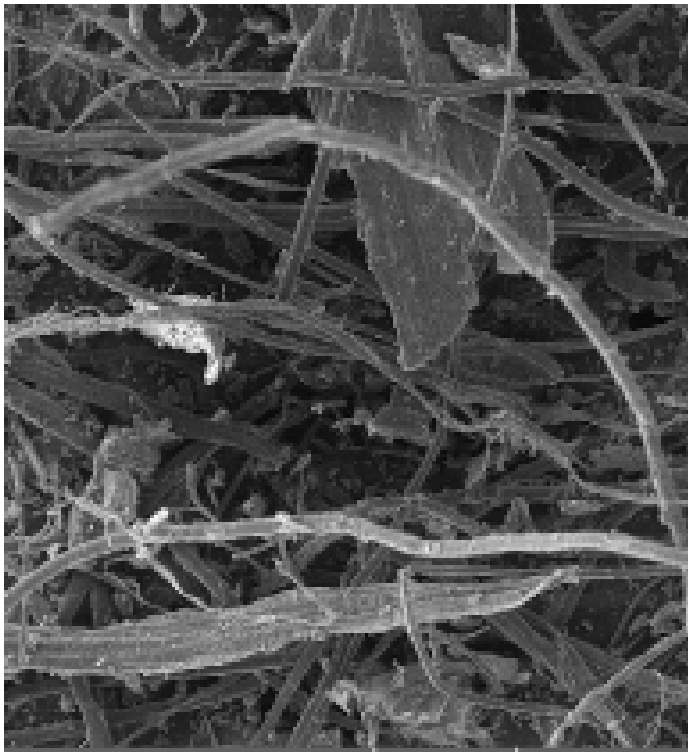

(b)

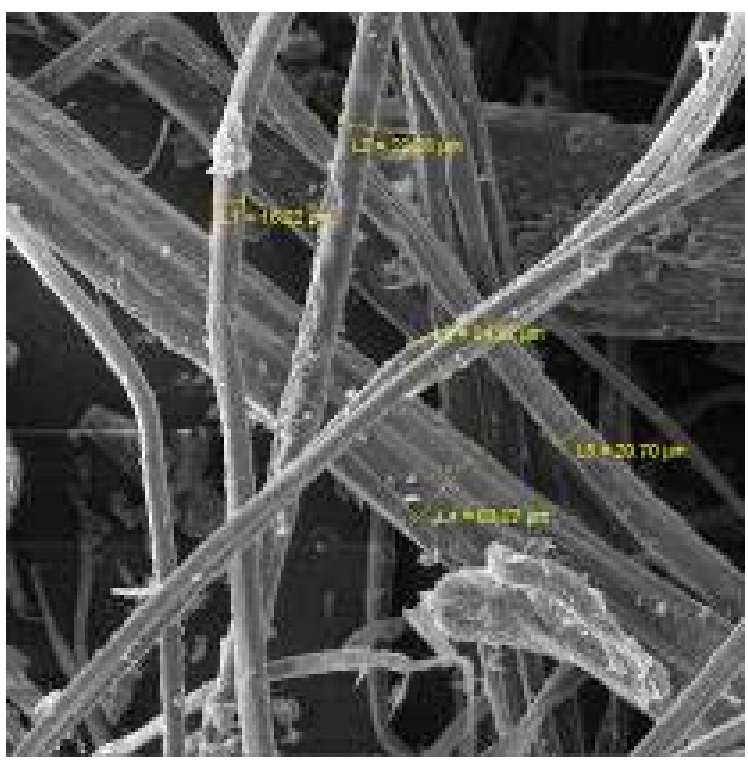

(c)

Figure 4. Photographs of flax under REM microscope (magnification $100 \times(\mathbf{a}), 200 \times(\mathbf{b})$, and $500 \times$ (c)).

As can be seen from the observed values, the thickness of both fiber types is very low. Especially in the case of flax, the thickness is significantly lower than those of common technical fibers of flax (where the thickness can be ten times higher). Thus, both fiber types are potentially interesting regarding the production of insulators suitable for VIPs. To produce the samples, polyester bi-component fibers with a thickness of $2.2 \mathrm{dTex}$, and with a $15 \%$ addition of raw fibers, were used. The raw fibers were homogenized and combined with bi-component fibers. Following this, samples were pressed from fibers at a temperature of $150{ }^{\circ} \mathrm{C}$. The aim was to reach the highest possible density of samples.

For the production of the samples, it was necessary to choose a suitable technology and temperature regime. First, differential scanning calorimetry analysis-DSC of the binder fibers was performed in order to determine the possible temperature range of their use. It was found that the fibers are active from about $80{ }^{\circ} \mathrm{C}$, and the total fusion of the fiber occurs at temperatures above $250{ }^{\circ} \mathrm{C}$ (see Figure 5). 


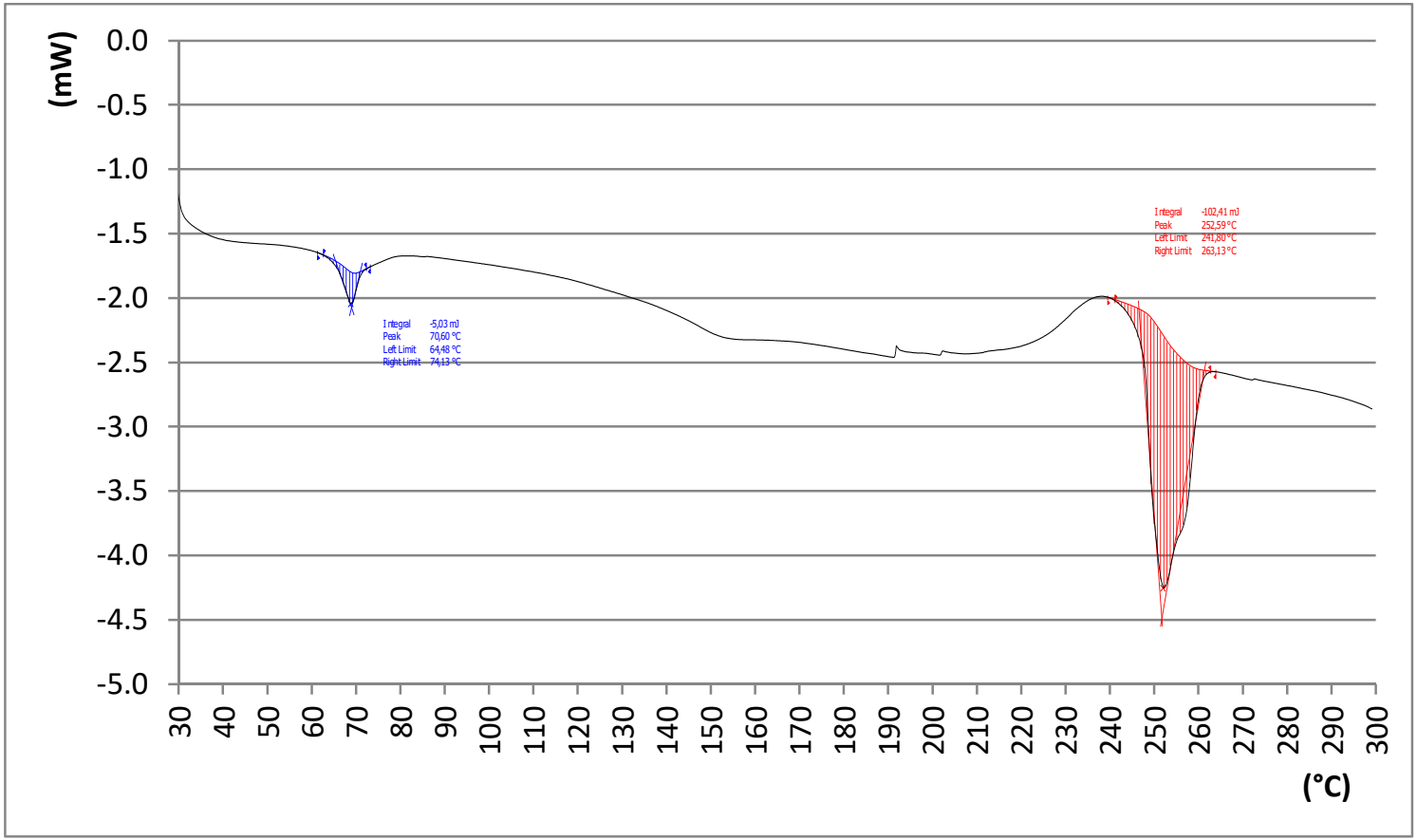

Figure 5. DSC analysis of bi-component bounding fiber.

Thus, an activation temperature of $150^{\circ} \mathrm{C}$ was chosen, which is also the minimum temperature required to completely dry the fibers to be successfully vacuumed. Several procedures for the production of insulators under laboratory conditions have been proposed to achieve the highest homogeneity of the samples. The following procedure was evaluated as the best and was subsequently applied in the production of all samples:

- manual homogenization of the fiber mixture;

- laminating the fibers into a steel mold and placing in an oven at $+150{ }^{\circ} \mathrm{C}$ for $20 \mathrm{~min}$;

- manual compression of the sample using the pressure plate;

- reinsertion in the oven at $+150^{\circ} \mathrm{C}$ for $20 \mathrm{~min}$;

- pressing the sample manually to the desired compression;

- demolding and placing in an oven at $+150^{\circ} \mathrm{C}$ for $10 \mathrm{~min}$;

- hand-pressing to the required thickness and cooling the sample.

A test sample of core insulators determination of basic physical properties was provided:

- determination of thickness under loading of 250 Pa of press in accordance with EN 823 [9];

- determination of linear dimensions and density in accordance with EN 12085 and EN 1602 [10,11];

- determination of compressive stress at 10\% strain in accordance with EN 826 [12];

- determination of compressibility in accordance with EN 12431 [13].

After production, there was a subsequent expansion (relaxation) in the samples, which was (as can be seen in Table 1) significantly higher in the case of cotton.

As is obvious from the results (see in Table 1), cotton-based samples have lower density and mechanical properties (including higher compressibility). In the case of flax-based samples, density is higher and the mechanical properties are better than in the cotton-based samples (including lower compressibility). The final mechanical properties of VIPs depend on final compression by atmospheric pressure after vacuuming (according to the results of measurement, it is possible to calculate final deformation after vacuuming of around $38 \%$ of initial thickness without loading in the case of flax, and $50 \%$ in the case of cotton). 
The dependence on pressure of thermal conductivity at a temperature gradient of $10{ }^{\circ} \mathrm{C}$ was determined on samples of core insulators in accordance with EN 12667 and ISO 8301 (by equipment Lasercomp FOX 200 Vacuum). The thermal conductivity was determined at normal pressure $(\mathrm{p}=1013.25 \mathrm{mbar}$ ) and then under vacuum at $0.05,0.5,1$, and $10 \mathrm{mbar}$ (see in Table 2).

Table 2. Dependence of thermal conductivity on pressure of test specimens.

\begin{tabular}{ccccc}
\hline Pressure (mbar) & \multicolumn{2}{c}{ Thickness of Test Specimens $(\mathbf{m m})$} & \multicolumn{2}{c}{$\begin{array}{c}\text { Thermal Conductivity of Test Specimens } \\
(\mathbf{m W} / \mathbf{( m} \cdot \mathbf{K}))\end{array}$} \\
\hline & Cotton & Flax & Cotton & Flax \\
\hline 0.05 & 15.062 & 10.300 & 5.146 & 4.451 \\
0.5 & 14.389 & 9.919 & 7.306 & 9.138 \\
1 & 14.446 & 9.893 & 14.300 & 12.467 \\
10 & 14.364 & 9.874 & 30.047 & 28.703 \\
Normal pressure & 14.776 & 9.614 & 41.903 & 43.423 \\
\hline
\end{tabular}

As can be seen from the results obtained, the test samples show very low thermal conductivities at a pressure of $5 \mathrm{~Pa}$, while the flax-based sample achieved better values. Its properties are, in practice, comparable to those of $\mathrm{SiO}_{2}$-based insulators. In this case, the higher bulk density has a positive effect where, after vacuuming, the thermal conductivity is significantly reduced compared to that of the cotton-based sample.

For the utilization of VIP in construction, dependence of thermal conductivity on temperature is very important. Tests for both types of insulator were carried out to determine thermal insulation properties under pressure of $5 \mathrm{~Pa}$, variables mean temperatures and temperature difference of $10 \mathrm{~K}$.

It is obvious that with elevating temperatures, there is no significant degradation of the thermal insulating properties of insulators in a vacuum. In both cases, thermal conductivity under temperatures up to $20^{\circ} \mathrm{C}$ was found to be lower compared with that in the standard $10^{\circ} \mathrm{C}$ (see Figure 6).

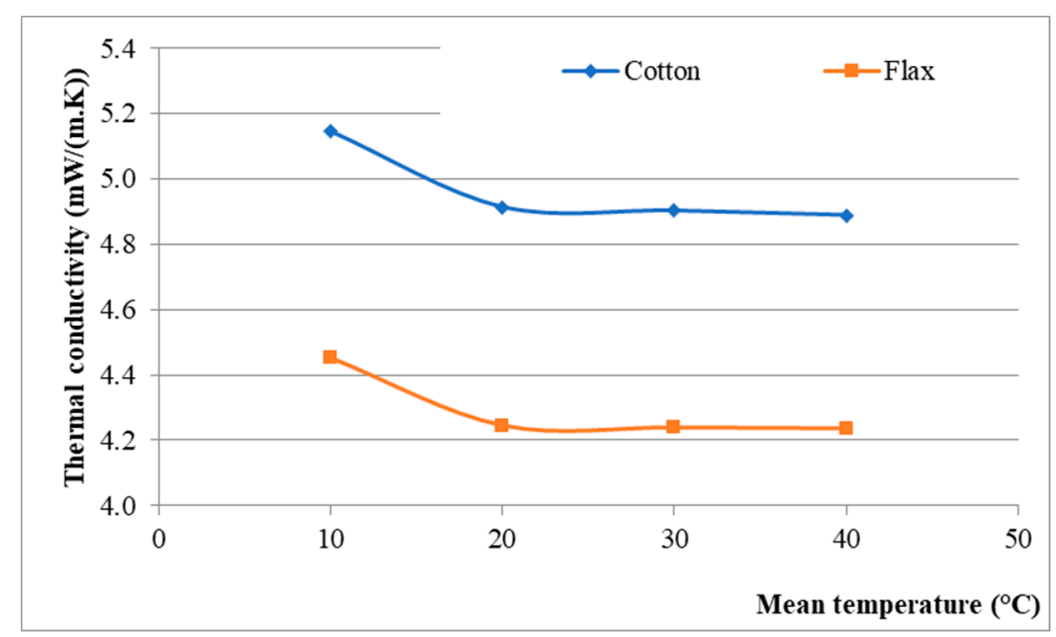

Figure 6. Dependence of thermal conductivity on mean temperature of samples based on cotton and flax.

Another important feature of using VIPs in building structures is the effect of fire on the product and its individual components (core insulator + casing). The basic test of reaction to fire uses a single-flame source according to EN ISO 11925-2 [14]. This test was carried out on samples of the core insulator and the final VIP based on a cotton-based insulator with utilization of aluminum-based film from the Hanita coatings company (internal pressure of $5 \mathrm{~Pa}$, without getter).

The surfaces of individual vertically oriented samples were exposed to the flame in the vertical axis of the test specimen, $40 \mathrm{~mm}$ above its bottom edge. A small burner was moved at a $45^{\circ}$ angle 
horizontally to the test specimen until the flame reached a pre-determined contact point. From the first contact of the specimen with the flame, the burner was allowed to operate for $15 \mathrm{~s}$, then it was removed.

The following elements were evaluated: the flame spread above $150 \mathrm{~mm}$ from the contact point of the test flame; the time in which it occurred; and the ignition of the filter paper located under the specimen. The possible flame spread was also monitored, within $20 \mathrm{~s}$ of applying the small burner flame (see Figures 7-9).

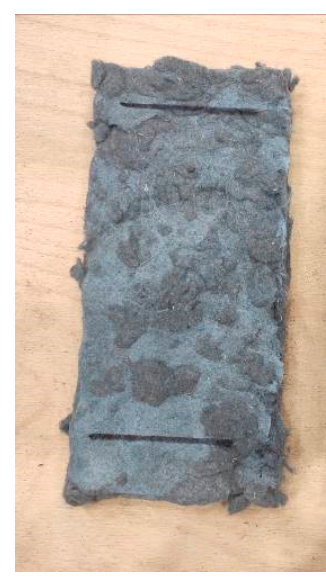

(a)

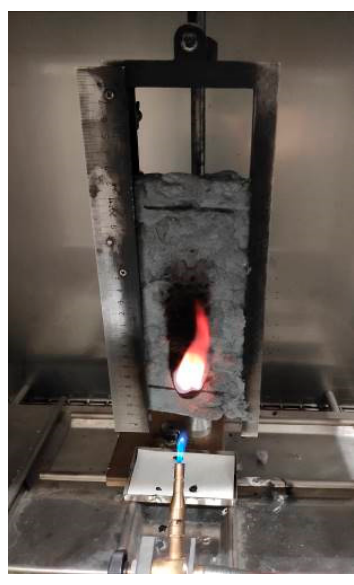

(b)

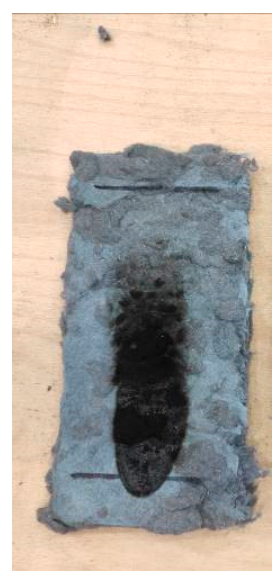

(c)

Figure 7. Samples of cotton-single-flame source test; (a) before test, (b) during test, and (c) after test.

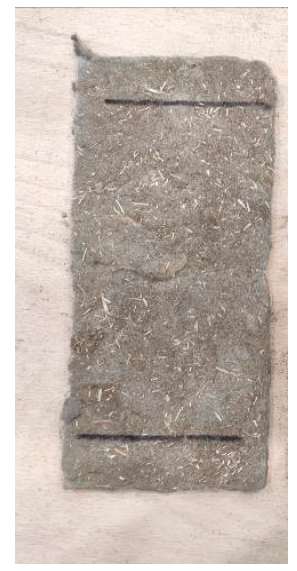

(a)

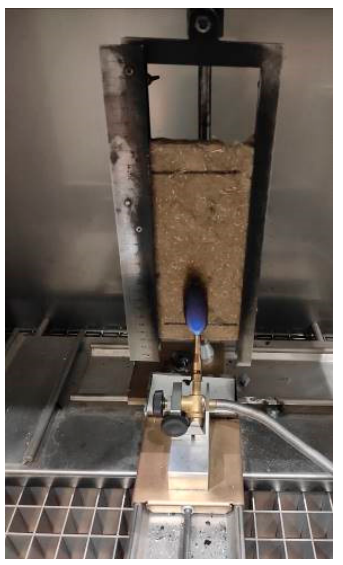

(b)

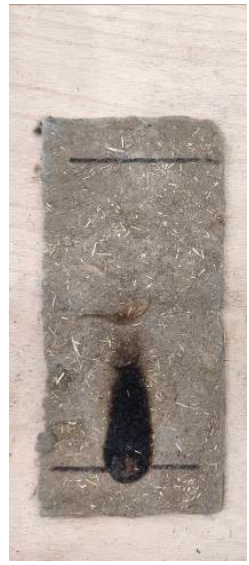

(c)

Figure 8. Samples of flax—single-flame source test; (a) before test, (b) during test, and (c) after test.

After the contact of the small flame, there was no burning in any of the samples. A threshold of $150 \mathrm{~mm}$ from the flame site had not been reached, and the filter paper did not burn (see in Table 3).

Table 3. Dependence of thermal conductivity on pressure of samples based on flax.

\begin{tabular}{lcccc}
\hline Sample & $\begin{array}{c}\text { Specimen Ignition } \\
\text { (Yes/No) }\end{array}$ & $\begin{array}{c}\text { Height of Flame } \\
\text { Tip [mm] }\end{array}$ & $\begin{array}{c}\text { Time[s] for the Flame to Reach a } \\
\text { Distance of 150 mm above the } \\
\text { Small Burner Impingement }\end{array}$ & $\begin{array}{c}\text { Filter Paper } \\
\text { Ignition (Yes/No) }\end{array}$ \\
\hline Cotton 1 & yes & 110 & - & no \\
Cotton 2 & yes & 90 & - & no \\
\hline Hemp 1 & yes & 50 & - & no \\
Hemp 2 & yes & 40 & - & no \\
\hline VIP envelope & no & - & & no \\
\hline
\end{tabular}




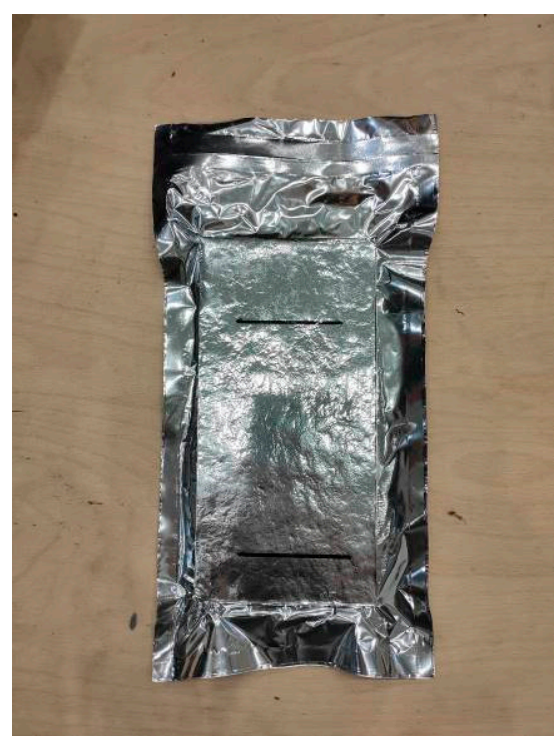

(a)

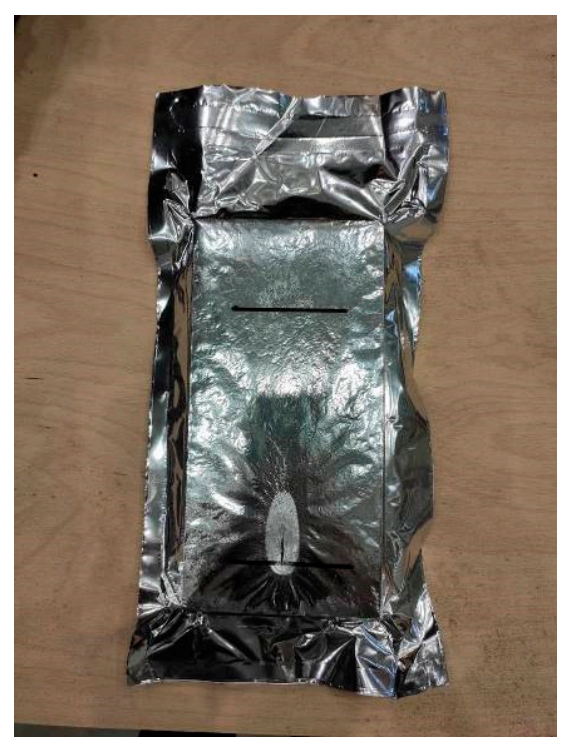

(b)

Figure 9. Samples of flax-single-flame source test; (a) before test and (b) after test.

\section{Discussion}

From the measured values, the dependencies were set (see Figures 10 and 11), and the evaluation of results and comparison of measured values with commercial insulators used for VIP production were performed.

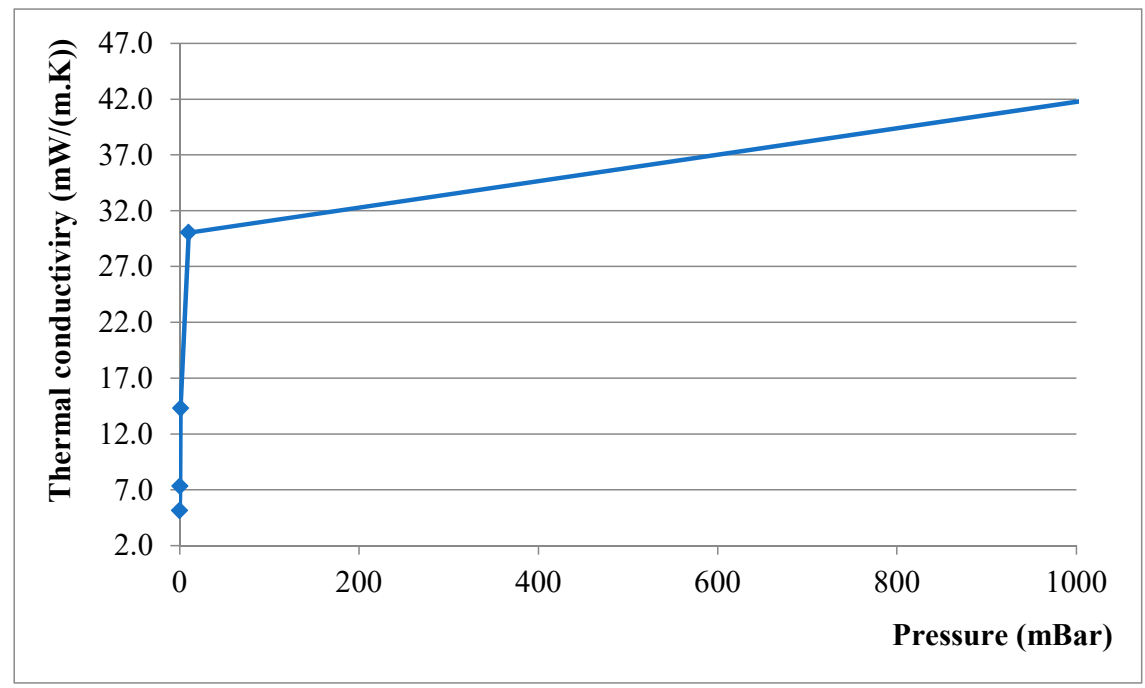

Figure 10. Dependence of thermal conductivity on pressure of samples based on cotton.

According to [8], pressure $\mathrm{p}_{1 / 2}[\mathrm{~Pa}]$ was evaluated (as the pressure at which the original value of thermal conduction increased by $12.75 \mathrm{~mW} /(\mathrm{m} . \mathrm{K})$ ). Calculated values are stated in the following Table 4.

Table 4. Properties of core insulators.

\begin{tabular}{ccc}
\hline Sample & $\begin{array}{c}\text { Thermal Conductivity } \\
\lambda_{\mathbf{0}}(\mathbf{m W} /(\mathbf{m} \cdot \mathbf{K}))\end{array}$ & $\begin{array}{c}\text { Pressure } \\
p_{\mathbf{1 / 2}}(\mathbf{m B a r})\end{array}$ \\
\hline Cotton & 5.146 & 2.47 \\
Flax & 4.451 & 2.81 \\
\hline
\end{tabular}




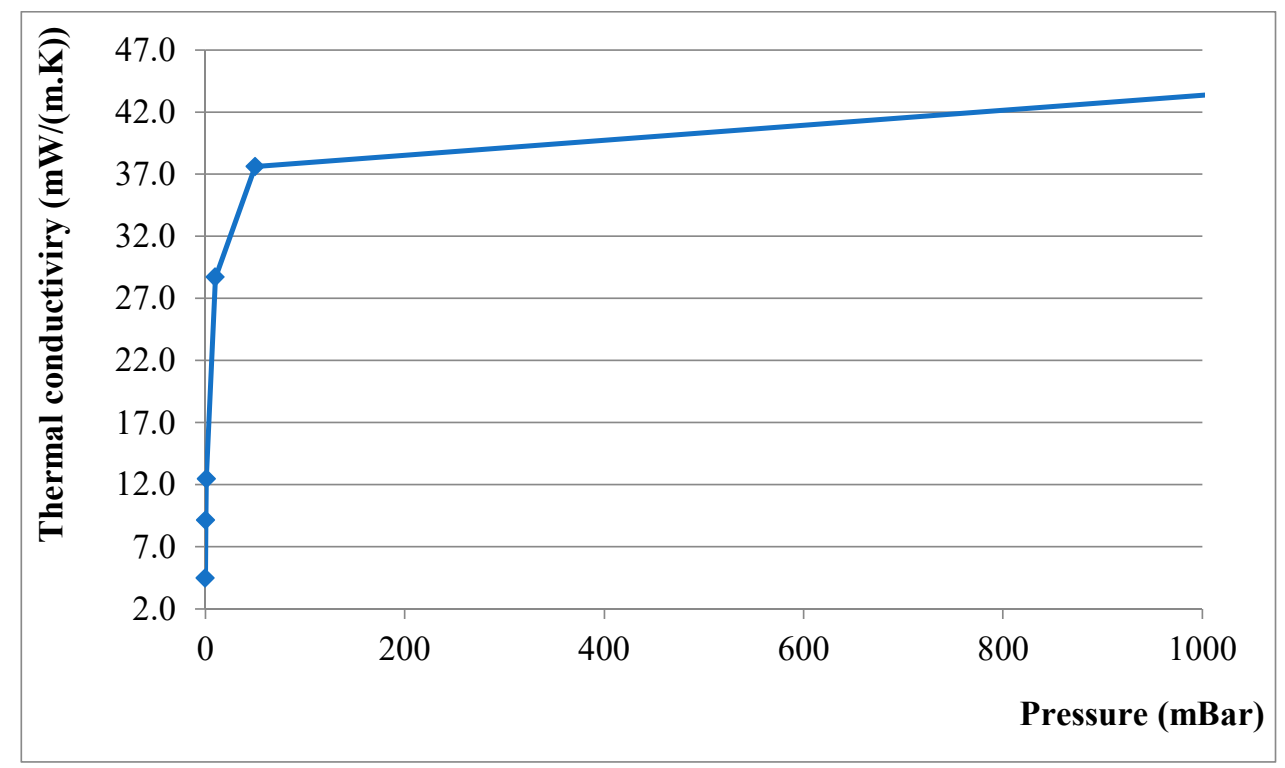

Figure 11. Dependence of thermal conductivity on pressure of samples based on flax.

As can be seen from the results, the obtained values of thermal conduction under vacuum $\left(\lambda_{0}\right)$ were relatively low and comparable to insulators based on $\mathrm{SiO}_{2}$. However, they did not reach extremely low values when compared with other materials, such as glass wool. Regarding the obtained values of pressures $p_{1 / 2}$, it can be observed that the pressures were relatively low. Therefore, the insulators are not suitable for common construction applications, and it would be necessary to use classical aluminum foil during installation.

\section{Conclusions}

Experimental works have proven that fibers based on flax and cotton (lint from a textile-tearing machine) can be an interesting and potentially advantageous secondary materials when used in the production of insulators for VIP. It was observed that during the treatment of technical fibers made of flax, pulping occurred, and the fibers caught in the filters had a thickness of approximately 19 microns, which is significantly less than the thickness of common hemp fibers (usually between 100 and 200 microns) [15].

Under normal thermal conductivity conditions, the experimentally-produced insulators exhibit $41.9-43.4 \mathrm{~mW} /(\mathrm{m} . \mathrm{K})$, which is a relatively high value compared to conventional mineral wool or polystyrol (mainly due to the high bulk density of insulators). They also demonstrate thermal conductivity of about 10x, which is a very good result. Therefore, these insulators are useful in VIP production. The density of samples, after vacunising, will be in the normal range typical for VIP insulators (with calculation of $38 \%$ compression, the density of the flax-based insulator will be $245 \mathrm{~kg} / \mathrm{m}^{3}$ and with calculation of $50 \%$ compression, the density of the cotton-based insulator will be $\left.238 \mathrm{~kg} / \mathrm{m}^{3}\right)$.

However, regarding their long-term properties, it is also necessary to evaluate the change in thermal conductivity depending on the pressure change within a VIP. The properties of newly developed insulators are comparable to those of glass wool, and to be used in building construction, cotton and linen fibers would need to be combined with $\mathrm{SiO}_{2}$.

Author Contributions: Conceptualization, J.Z. and V.N.; methodology, J.Z.; validation, J.Z., J.P. and V.N.; formal analysis, J.Z.; investigation, J.B.; resources, J.P.; data curation, J.Z.; writing-original draft preparation, J.Z. and J.P.; writing-review and editing, J.Z. and V.N.; visualization, V.N.; supervision, J.Z.; project administration, J.Z.; funding acquisition, J.Z. All authors have read and agreed to the published version of the manuscript.

Funding: This research was funded by Czech science foundation, grant number GA 17-00243S "Study of the behaviour of insulating materials under extremely low pressure" and by Brno University of Technology, 
grant number FAST-S-20-6370 "Development of vakuum insulation based on by-products". For taking measurements, equipment was bought with the support of the project CZ.1.05/2.1.00/19.0406 'AdMaS-improvement of research capacities' was used.

Conflicts of Interest: The authors declare no conflict of interest.

\section{References}

1. Baetens, R.; Jelle, B.P.; Thue, J.V.; Tenpierik, M.J.; Grynning, S.; Uvsløkk, S.; Gustavsen, A. Vacuum insulation panels for building applications: A review and beyond. Energy Build. 2010, 42, 147-172. [CrossRef]

2. Brunner, S.; Wakili, K.G.; Stahl, T.; Binder, B. Vacuum insulation panels for building applications-Continuous challenges and developments. Energy Build. 2014, 85, 592-596. [CrossRef]

3. Fricke, J.; Buttner, D.; Caps, R.; Gross, J.; Nilsson, O. Solid conductivity of loaded fibrous insulations. In Insulation Material, Testing and Application; ASTM International: West Conshohocken, PA, USA, 1990; pp. 66-78.

4. Sung Kwon, J.; Hyo Jang, C.; Jung, H.; Ho Song, T. Effective thermal conductivity of various filling materials for vacuum insulation panels. Int. J. Heat Mass Transf. 2009, 52, 5525-5532. [CrossRef]

5. Nemanič, V.; Žumer, M. New organic fibre-based core material for vacuum thermal insulation. Energy Build. 2015, 90, 137-141. [CrossRef]

6. Zach, J.; Peterkova, J.; Bubenik, J. Study of behaviour of thermal insulation materials under extremely low pressure. In Proceedings of the 4th Central European Symposium on Building Physics (CESBP 2019), Prague, Czech Republic, 2-5 September 2019; p. 282.

7. Zach, J.; Peterkova, J.; Dufek, Z.; Sekavčnik, T. Development of vacuum insulating panels (VIP) with non-traditional core materials. Energy Build. 2019, 199, 12-19. [CrossRef]

8. Shufer, E. Thermal Conductivity of VIPs as a Function of Internal Pressure. In Thermal Conductivity as a Function of Pressure; Hanita Coatings: Hanita, Israel, 2015; pp. 1-7.

9. European Committee for Standardization. EN 823 Thermal Insulating Products for Building Applications-Determination of Thickness; European Committee for Standardization: Brussels, Belgium, 2013.

10. European Committee for Standardization. EN 1602 Thermal Insulating Products for Building Applications-Determination of the Apparent Density; European Committee for Standardization: Brussels, Belgium, 2013.

11. European Committee for Standardization. EN 12085 Thermal Insulating Products for Building Applications-Determination of Linear Dimensions of Test Specimens; European Committee for Standardization: Brussels, Belgium, 2013.

12. European Committee for Standardization. EN 826 Thermal Insulating Products for Building Applications-Determination of Compression Behaviour; European Committee for Standardization: Brussels, Belgium, 2013.

13. European Committee for Standardization. EN 12431 Thermal Insulating Products for Building Applications-Determination of Thickness for Floating Floor Insulating Products; European Committee for Standardization: Brussels, Belgium, 2013.

14. European Committee for Standardization. EN ISO 11925-2 Reaction to Fire Tests-Ignitability of Building Products Subjected to Direct Impingement of Flame-Part 2: Single-Flame Source Test; European Committee for Standardization: Brussels, Belgium, 2010.

15. Kymäläinen, H.-R.; Sjöberg, A.-M. Flax and hemp fibres as raw materials for thermal insulations. Build. Environ. 2008, 43, 1261-1269. [CrossRef] 